\title{
ANALISIS TINGKAT KEPUASAN ANGGOTA TERHADAP PELAYANAN PADA KOPERASI GARDU TANI DI DESA KETAPANG, KECAMATAN SUSUKAN, KABUPATEN SEMARANG
}

\author{
(Analysis of Satisfaction of Cooperative Member to "Gardu Tani” Cooperative Service in \\ Al-Barokah Farmers Association, Ketapang Village, Susukan District, Semarang Regency)
}

Bunga Anadesta Hanri Putri, Bambang Trisetyo Eddy, Tutik Dalmiyatun

Program Studi Agribisnis Fakultas Peternakan dan Pertanian Universitas Diponegoro

Kampus drh. R. Soejono Koesoemowardojo Tembalang Semarang

Email : bungaanadesta_hanriputri@yahoo.com

Diterima 06 Februari 2018, disetujui 17 April 2018

\begin{abstract}
ABSTRAK
Penelitian ini bertujuan menganalisis tingkat kepuasaan anggota terhadap pelayanan Koperasi Gardu Tani di Desa Ketapang, Kecamatan Susukan, Kabupaten Semarang. Penelitian ini dilaksanakan pada bulan September - Oktober 2017 di Paguyuban Al-Barokah. Metode yang digunakan dalam penelitian adalah survai. Penentuan lokasi penelitian secara purposive, pemilihan responden dilakukan secara acak (Simple Random Sampling). Jumlah responden ditentukan menggunakan rumus Slovin sebanyak 77 orang. Teknik pengumpulan data menggunakan kuesioner, wawancara, dan observasi teknik analisis data menggunakan analisis IPA (Important Performance Analysis) dan CSI (Customer Satisfaction Index). Berdasarkan analisis IPA, atribut yang masih perlu ditingkatkan koperasi seperti kelengkapan fasilitas koperasi (Atribut Bukti Nyata), ketepatan waktu dalam mendapatkan uang hasil penjualan (Atribut Kehandalan), keterampilan atau pengetahuan pengurus (Atribut Jaminan), sanksi untuk anggota yang tidak mematuhi peraturan koperasi (Atribut Daya Ketanggapan) dan bantuan sosial seperti biaya rumah sakit bila ada anggota yang sakit (Dimensi Perhatian). Perhitungan CSI keseluruhan mencapai nilai 77,40\% dalam rentang skala 61-80 \%-anggota merasa puas terhadap kinerja yang diberikan koperasi.
\end{abstract}

Kata Kunci : kinerja, kepuasan, pelanggan.

\begin{abstract}
This study aims to analyze the level of member satisfaction with the service of farmer substation cooperatives in Ketapag village, Susukan district, Semarang district. This research was conducted in September - October 2017 in the Al-Barokah Circle of Friends. The methond used in the research is survey. Determination of the research location pyrposively, the selection of respondents was done randomly (Simple Random Sampling). the number of respondents was determined using the Slovin formula as many as 77 people. Data collection techiques using qustionnaires, interviews, and observation. Data analysis techniques using IPA (Important
\end{abstract}


Performance Analysis) and CSI (Customer Satisfaction Index). Based on IPA analysis, attributes that still need to be improved by cooperatives were cooperative facilities (Tangibles Attribute), timeliness in earning money from sales (Reliability Attribute), skills or knowledge of the board (Assurance Attribute), sanctions for members who do not comply with cooperative regulations and social assistance such as hospital fees when there are members who are sick (Empathy Attribute). Based on calculations, CSI extent reaches $77.40 \%$ in the range of $61-80 \%$ scale so that it can be said members are satisfied with the performance provided cooperatives.

Keywords: performance, satisfaction, customer.

\section{PENDAHULUAN}

Salah satu kelembagaan ekonomi yang dekat dengan petani adalah koperasi.Koperasi sendiri adalah suatu organisasi ekonomi yang dimiliki dan dioperasikan oleh seorang demi kepentingan bersama. Pada pasal 33 ayat 1 UUD 1945 dijelaskan bahwa perekonomian disusun sebagai usaha bersama berdasar atas asas kekeluargaan, sehingga sebagai salah satu pelaku ekonomi, koperasi diharapkan mampu menjadi soko guru perekonomian Indonesia (Riani, 2007). Koperasi merupakan perkumpulan otonom dari orang-orang yang bergabung secara sukarela untuk memenuhi kebutuhan ekonomi, sosial dan budaya mereka. Melalui koperasi, berbagai program pengembangan bisa dijalankan secara berskala dan dapat berkembang besar. Koperasi dikatakan ideal ketika koperasi melakukan pelayanan jasa yang diterima melampui harapan anggota, namun sebaliknya apabila jasa yang diterima lebih rendah dari pada yang diharapkan, maka kualitas pelayanan yang dipersepsikan buruk. Faktor yang mempengaruhi suatu pelayanan yang berkualitas terutama jasa yang diterima sesuai yang diharapkan,kualitas pelayanan yang baik dan memuaskan (Umar, 2003). Badan usaha koperasi memiliki keunikan yang tidak dimiliki oleh badan usaha lainnya yakni anggota koperasi sebagai pelanggan dan juga sekaligus sebagai pemilik koperasi (Ropke, 2000).

Koperasi Serba Usaha (KSU) bergerak pada usaha meminjamkan modal berupa benih dan bibit, pengadaan sarana dan produksi, menampung sisa hasil usaha serta memberikan informasi peluang pasar.
Koperasi yang belum optimal dalam melakukan pelayanan akan mengakibatkan menurunnya tingkat kepuasaan anggota. Kepuasaan anggota koperasi dirasa sangat penting agar koperasi mampu menilai kinerja yang diberikan apakah sudah memberikan kepuasan atau belum maka dibutuhkan suatu analisis mengenai tingkat kepuasan anggota koperasi terhadap tingkat pelayanan. Kepuasan berupa barang atau jasa dapat memuaskan konsumen (Irawan, 2002).

Kelembagaan pertanian di Desa Ketapang dalam mewujudkan salah satu Paguyuban dengan mendirikan koperasi dimana anggotanya adalah para petani di AlBarokah. Koperasi ini dibangun untuk memfasilitasi anggota guna mencukupi kebutuhan untuk bertani, koperasi menyediakan benih, bibit, pupuk serta koperasi juga sebagai wadah untuk para petani menjualkan hasil panennya. Tujuan penelitian ini adalah untuk mengetahui tingkat kepuasan anggota terhadap pelayanan koperasi Gardu Tani di Paguyuban AlBarokah, Desa Ketapang, Kecamatan Susukan, Kabupaten Semarang. Manfaat dari penelitian ini adalah sebagai bahan informasi mengenai tingkat kepuasaan anggota terhadap pelayanan Koperasi Gardu Tani koperasi dan memerikan tambhan informasi mengenai pelayanan koperasi serta diharapkan mampu menjadi referensi untuk penelitian mendatang.

\section{METODE PENELITIAN}

Metode yang digunakan dalam penelitian adalah survai. Lokasi ditentukan menggunakan metode purposive. Paguyaban 
Al-Barokah merupakan salah satu daerah pertanian organik yang cukup besar serta memiliki koperasi yang memenuhi kebutuhan dan menampung hasil panen dari anggota. Populasi penelitian ini adalah keseluruhan anggota koperasi di Paguyuban Al-Barokah dengan jumlah 343 anggota. Metode untuk jumlah sampel dengan menggunakan rumus slovin dengan batas kesalahan 10 persen (Sugiyono, 2013) dan menghasilkan jumlah sampel sebesar 77 responden. Data dikumpulkan dengan kuesioner. Wawancara dilakukan guna mendapatkan gambaran yang lebih jelas kondisi lapangan (Singarimbun, 2006). Penelitian dilaksanakan pada bulan September - Oktober 2017.

\section{ANALISIS DATA}

\section{Important Performance Analysis (IPA)}

Important Performance Analysis (IPA) adalah suatu metode untuk menganalisis sejauh mana tingkat kepuasaan anggota terhadap kinerja aktual (Supranto, 2001). Analisis kesesuaian digunakan untuk mengetahui urutan prioritas atribut-atribut yang menjadi prioritas perbaikan berdasarkan persentase perbandingan antara nilai kinerja dengan tingkat kepentingan atribut dimensi kualitas, menggunakan. Rumus Supranto (2001) adalah:

$$
X i=\frac{\sum X i}{n} \text { dan } Y i=\frac{\sum Y i}{n}
$$

Tabel 1. Customer Satisfaction Index (CSI)
Keterangan :

$\mathrm{Xi}=$ Total skor rata-rata tingkat kinerja aktual/pelaksanaan pada responden ke-i

Yi = Total skor rata-rata tingkat kepentingan pada responden ke-i

$\mathrm{n} \quad=$ Jumlah Responden

\section{Customer Satisfaction Index (CSI)}

Customer Satisfaction Index (CSI) digunakan untuk menentukan tingkat kepuasan konsumen secara menyeluruh dengan pendekatan yang mempertimbangkan tingkat kepentingan variabel-variabel yang diukur (Irawan, 2002). Indeks kepuasan pelanggan (CSI) dapat dihitung dengan tahapan berikut :

Perhitungan keseluruhan Customer Satisfaction Index (CSI) diilustrasikan pada Tabel (1). Dilihat pada nilai rata-rata pada kolom Kepentingan (I) dan kolom Kepuasan (P) yang sebelumnya dijumlahkan terlebih dahulu sesuai dengan atributnya sehingga diperoleh (Y). Pada kolom Skor (S) didapatkan dari kolom Kepentingan (I) dikalikan dengan kolom Kepuasan (P) per atribut dan hasilpenjumlahan dari per atribut didapatkan (T). CSI selanjutnyadiperoleh dari (Lodhita, 2014):

$$
C S I=\frac{T}{5(Y)} \times 100 \%
$$

Keterangan :

$\mathrm{T}=$ Hasil penjumlahan per atribut

5 = Nilai maksimum yang digunakan pada skala pengukuran

$\mathrm{Y}=$ Total penjumlahan dari kepentingan dan Kepuasan

\begin{tabular}{cccc}
\hline Atribut & $\begin{array}{c}\text { Kepentingan (I) } \\
\text { Skala }: 1-5\end{array}$ & $\begin{array}{c}\text { Kepuasan }(\mathrm{P}) \\
\text { Skala }: 1-5\end{array}$ & $\begin{array}{c}\text { Skor }(\mathrm{S}) \\
(\mathrm{S})=(\mathrm{I}) \mathrm{X}(\mathrm{P})\end{array}$ \\
\hline$\ldots \ldots .$. & & \\
$\ldots \ldots$. & & \\
$\ldots \ldots \ldots$ & & \\
$\ldots \ldots \ldots$ & & \\
Skor Total & Total $(\mathrm{I})=(\mathrm{Y})$ & Total $(\mathrm{S})=(\mathrm{T})$ \\
\hline
\end{tabular}


Skala kepuasan pelanggan/anggota yang umum dipakai dalam interpretasi indeks dapat dilihat pada Tabel 2 dibawah ini:

Tabel 2. Kriteria Indeks Kepuasan Pelanggan

\begin{tabular}{lc}
\hline \multicolumn{1}{c}{ Tingkat Kepuasan } & Skor \\
\hline Sangat Puas & $81-100$ \\
Puas & $61-80$ \\
Cukup & $41-60$ \\
Tidak Puas & $1-40$ \\
Sangat tidak Puas & $0-20$ \\
\hline
\end{tabular}

\section{HASIL DAN PEMBAHASAN}

\section{Identitas Responden}

Identitas responden yang dijadikan pokok utama dalam penelitian ini adalah umur, jenis kelamin, tingkat pendidikan. Hasil survai dilapangan menunjukkan bahwa pada rentang umur 21-30 tahun berjumlah 8 orang (10\%), 31-40 tahun sebanyak 11 orang (15\%), 41-50 tahun sebanyak 27 orang (35\%), dan rentang umur $>50$ tahun sebanyak 31 orang (40\%). Responden penelitian didominasi oleh laki-laki yaitu sebanyak 56 orang (72\%) sedangkan jumlah responden perempuan sebanyak 21 orang (28\%). Sebanyak 16 orang responden $(20 \%)$ tidak tamat sekolah, 22 orang $(28 \%), 19$ orang $(26 \%)$ tamat SMP, 18 orang $(24 \%)$ tamat SMA, dan 2 orang $(2 \%)$ lulusan dari perguruan tinggi.

\section{Analisis IPA (Important Performace}

\section{Analysis)}

Analisis IPA dalam penelitian ini meliputi 5 dimensi yaitu Tangibles, Reliability, Assurance, Responsiveness dan Empathy. Dimensi Tangibles menunjukkan enam atribut terkait dengan bukti fisik koperasi. Terdapat 4 atribut yang menunjukkan penilaian kondisi aktual lebih tinggi dari skor harapan yaitu atribut 2, 4, 5 dan 6. Atribut ke 5 pada kondisi aktual memiliki skor 3,63 yang menurut anggota sudah baik dalam kualitas mutu barang yang ditawarkan. Responden beranggapan bahwa dengan kualitas atau mutu barang yang baik dapat memberikan dampak positif. Hasil penelitian ini sesuai dengan pendapat Supranto (2006) yaitu bentuk pelayanan yang baik dapat menimbulkan prestasi kinerja yang diberikan. Nilai positif dari Tangibles menunjukkan semakin tinggi bukti yang diberikan maka semakin tinggi pula kepuasan konsumen. Hal ini sesuai dengan pendapat Wayan (2008) yang menyatakan bahwa bukti fisik memiliki pengaruh yang besar terhadap kepuasan pelanggan. Adapun kondisi aktual dan harapan dimensi Tangibles lebih jelas dapat dilihat pada Tabel 3.

Dimensi Realiability memiliki 5 atribut menunjukkan terkait bukti fisik koperasi. Dimensi Reliability memiliki tingkat kondisi aktual tertinggi sebesar 3,57 yang terdapat pada dimensi ke 2 yaitu ketepatan waktu dalam mendapatkan hasil penjualan, hal ini menunjukkan bahwa didalam dimensi ini dirasa berhasil dalam memberikan pelayanan

Tabel 3. Hasil Perhitungan Nilai Rata-rata Kondisi Aktual dan Harapan (Sumber : Hasil Olah Data, 2017).

\begin{tabular}{clcc}
\hline No & \multicolumn{1}{c}{ Atribut } & Kondisi Aktual & Harapan \\
\hline 1. & Penampilan (kerapian) pengurus koperasi & 3,51 & 3,63 \\
2. & Kebersihan dan kenyamanan ruang koperasi & 3,49 & 3,48 \\
3. & Kelengkapan fasilitas koperasi (timbangan, alat & 3,37 & 3,54 \\
& angkut, uji lab,dll) & 3,53 & 3,51 \\
4. & Barang kebutuhan yang disediakan di koperasi & 3,63 & 3,50 \\
5. & Kualitas/mutu barang yang ditawarkan koperasi & 3,57 & 3,51 \\
6. & Kemudahan untuk memperoleh informasi & mengenai koperasi (buku petunjuk/leaflet) & \\
\hline
\end{tabular}


yang diberikan. Karena menurut pendapat Sunarto (2006) salah satu faktor kecepatan melayani konsumen seperti kenyaman yang diberikan, kemudahan lokasi, kemudahan memperoleh hasil penjualan, serta harga yang wajar. Adapun kondisi aktual dan harapan dimensi Realiability lebih jelas dapat dilihat pada Tabel 4.

Dimensi Assurance memiliki beberapa atribut yang dirasa berpengaruh untuk mendapatkan kepuasaan, seperti kejujuran, keterampilan, pembagian Sisa Hasil Usaha (SHU), transparansi SHU, keramahan pengurus. Dimensi Assurance jika dilihat pada atributnya yang memiliki skor kondisi aktual lebih tinggi dibandingkan dengan harapan terdapat pada datribut 1,3,4 dan 5 . Atribut yang memiliki skor tertinggi pada pembagian Sisa Hasil Uaha (SHU) secara adil sebesar 3,79. Hal ini menunjukkan bahwa faktor dimensi jaminan seperti tingkah laku, sopan santun, cara menyampaikan yang jelas, waktu penyampaian yang tepat, keramahan pengurus serta keterampilan pengurus yang baik (Supranto, 2001). Adapun kondisi aktual dan harapan dimensi Assurance lebih jelas dapat dilihat pada Tabel 5.

Dimensi Responsiveness menunjukkan lima atribut terkait dengan bukti fisik koperasi. Dimensi ini memiliki kemampuan untuk membantu dan memberikan pelayanan secara cepat dan tepat kepada pelanggan dengan melalui penyampaian informasi yang jelas. Jika dilihat atribut ini memiliki score tertinggi pada persyaratan yang mudah untuk menjual hasil pertanian ke koperasi sebesar 3,71 berarti suatu keinginan para pengurus untuk membantu para anggota serta memberikan pelayanan dengan tanggap, sehingga mampu menciptakan rasa puas (Fandy, 2012). Nilai positif dari keandalan menunjukkan semakin baik keandalan yang diberikan, maka akan diikuti dengan semakin baiknya peningkatan kepuasan pelanggan. Koperasi Gardu Tani sudah mampu menciptakan kepuasaan pelanggan. Adapun kondisi aktual dan harapan dimensi Responsiveness lebih jelas dapat dilihat pada Tabel 6.

Dimensi emphaty terdapat lima atribut

Tabel 4. Hasil Perhitungan Nilai Rata-rata Kondisi Aktual dan Harapan Dimensi Reliability Tahun 2017 (Sumber: Hasil Olah Data, 2017).

\begin{tabular}{|c|c|c|c|}
\hline No & Atribut & Kondisi Aktual & Harapan \\
\hline & $\begin{array}{l}\text { Kemudahan dalam pendaftaran anggota baru dan } \\
\text { kemudahan melakukan transaksi jual atau beli }\end{array}$ & 3,67 & 3,62 \\
\hline 2. & $\begin{array}{l}\text { Ketepatan waktu dalam mendapatkan uang hasil } \\
\text { penjualan }\end{array}$ & 3,57 & 3,63 \\
\hline 3. & Terdapat penetapan harga jual & 3,66 & 3,68 \\
\hline & $\begin{array}{l}\text { Pelaksanaan rapat anggota tahunan (RAT) dan } \\
\text { pembagian SHU tepat waktu }\end{array}$ & 3,68 & 3,71 \\
\hline 5. & Lokasi koperasi strategis untuk di tempuh & 3,72 & 3,54 \\
\hline
\end{tabular}

Tabel 5. Hasil Perhitungan Nilai Rata-rata Kondisi Aktual dan Harapan Dimensi Assurance

\begin{tabular}{llcc}
\hline No & \multicolumn{1}{c}{ Atribut } & Kondisi Aktual & Harapan \\
\hline 1. & Kejujuran pengurus koperasi & 3,75 & 3,67 \\
2. & Ketrampilan/pengetahuan pengurus & 3,57 & 3,68 \\
3. & Pembagian SHU secara adil & 3,79 & 3,66 \\
4. & Transparansi laporan hasil usaha & 3,66 & 3,65 \\
5. & Keramahan pengurus dalam melayani anggota & 3,76 & 3,55 \\
\hline
\end{tabular}


Tabel 6. Hasil Perhitungan Nilai Rata-rata Kondisi Aktual dan Harapan Dimensi Responsiveness

\begin{tabular}{rlcc}
\hline No & \multicolumn{1}{c}{ Atribut } & Kondisi Aktual & Harapan \\
\hline 1. & Persyaratan yang mudah untuk menjual barang ke & 3,71 & 3,70 \\
& koperasi & 3,67 & 3,67 \\
2. Pembayaran penjualan barang yang cepat & 3,63 & 3,68 \\
3. Sanksi untuk anggota yang tidak mematuhi aturan & 3,70 & 3,64 \\
& koperasi & 3,68 & 3,72 \\
4. Penyampaian informasi secara jelas oleh pengurus & Kecepatan dan ketepatan pengurus dalam & & \\
5. menanggapai keluhan anggota & & & \\
\hline
\end{tabular}

Tabel 7. Hasil Perhitungan Nilai Rata-rata Kondisi Aktual dan Harapan Dimensi Empathy (Sumber: Hasil Olah Data, 2017).

\begin{tabular}{rlcc}
\hline No & \multicolumn{1}{c}{ Atribut } & Kondisi Aktual & Harapan \\
\hline 1. & Bingkisan Hari Raya & 3,61 & 3,68 \\
2. & $\begin{array}{l}\text { Peminjaman sarana produksi (pupuk, pestisida, } \\
\text { benih,dll) }\end{array}$ & 3,44 & 3,51 \\
3. & $\begin{array}{l}\text { Kesabaran anggota dalam melayani dan merespon } \\
\text { anggota }\end{array}$ & 3,64 & 3,62 \\
4. & Keramahaan pengurus dalam melayani anggota \\
5. & Bantuan sosial seperti biaya rumah sakit bila ada & 3,70 & 3,66 \\
& anggota yang sakit & 3,42 & 3,51 \\
\hline
\end{tabular}

terkait bukti fisik koperasi. Dimensi Emphaty memiliki kondisi aktual tertinggi dibandingkan dengan skore harapan terletak pada atribut ke 4 dengan skore 3,70 yaitu keramahan pengurus dalam melayani anggota. Keramahan disini seperti bertegur sapa, senyum dan memberikan keramahan kepada setiap anggota yang datang ke koperasi. Hal ini sesuai dengan penelitian Lupiyoadi (2014). Koperasi yang baik, jika dilihat dari kelima dimensi yang ada maka keseluruhan dimensi mampu memberikan informasi-informasi yang baik untuk koperasi yang akan datang seperti hal anggota mampu memberikan tanggapan dengan munculnya rasa kepercayaan dan keyakinan anggota terhadap pengurus koperasi, memberikan pandangan untuk kemajuan dari koperasi, mampu memberikan pengaruh positif kepada pengurus koperasi dengan memberikan keramahan selama memperoleh pelayanan di koperasi. Adapun kondisi aktual dan harapan dimensi Responsiveness lebih jelas dapat dilihat pada Tabel 7.

\section{Analisis CSI (Customer Satisfaction Index)}

Customer Satisfaction Index (CSI) digunakan untuk menentukan tingkat kepuasan konsumen secara menyeluruh dengan pendekatan yang mempertimbangkan tingkat kepentingan variabel-variabel yang diukur (Irawan, 2002). CSI diperlukan untuk mengetahui tingkat kepuasan pengguna secara menyeluruh dengan memperhatikan tingkat kepentingan dari atribut-atribut produk atau jasa. Hasil Perhitungan CSI (Customer Satisfaction Index) dapat dilihat pada Tabel 8. Berdasarkan Tabel 8 menunjukkan pada Dimensi Tangibles memiliki nilai harapan dengan skor 3,63 yang menurut anggota sudah baik dalam kualitas mutu barang yang ditawarkan. Responden 


\begin{tabular}{|c|c|c|c|}
\hline Atribut & Harapan (I) & Kinerja $(\mathrm{P})$ & Skor (IxP) \\
\hline \multicolumn{4}{|l|}{ Dimensi Tangible (bukti fisik) } \\
\hline 1. Penampilan (kerapian) pengurus koperasi & 3,63 & 3,51 & 12,74 \\
\hline 2. Kebersihan dan kenyamanan ruang koperasi & 3,48 & 3,49 & 12,14 \\
\hline $\begin{array}{l}\text { 3. Kelengkapan fasilitas koperasi (timbangan, alat angkut, uji } \\
\text { lab, dll) }\end{array}$ & 3,54 & 3,37 & 11,92 \\
\hline 4. Barang kebutuhan yang disediakan di koperasi & 3,51 & 3,53 & 12,39 \\
\hline 5. Kualitas/mutu barang yang ditawarkan koperasi & 3,50 & 3,63 & 12,39 \\
\hline $\begin{array}{l}\text { 6. Kemudahan untuk memperoleh informasi mengenai } \\
\text { koperasi (buku petunjuk/leaflet) }\end{array}$ & 3,51 & 3,57 & 12,53 \\
\hline \multicolumn{4}{|l|}{ Dimensi Reliability (Keandalan) } \\
\hline $\begin{array}{l}\text { 7. Kemudahan dalam pendaftaran anggota baru dan } \\
\text { kemudahan melakukan transaksi jual atau beli }\end{array}$ & 3,62 & 3,67 & 12,53 \\
\hline 8. Ketepatan waktu dalam mendapatkan uang hasil penjualan & 3,63 & 3,57 & 12,95 \\
\hline 9. Terdapat penetapan harga jual & 3,68 & 3,66 & 13,46 \\
\hline $\begin{array}{l}\text { 10. Pelaksanaan rapat anggota tahunan (RAT) tepat } \\
\text { waktudanpembagian SHU tepatwaktu }\end{array}$ & 3,71 & 3,68 & 13,65 \\
\hline 11 Lokasi koperasi strategis untuk di tempuh & 3,54 & 3,72 & 13,16 \\
\hline \multicolumn{4}{|l|}{ Dimensi Assurance (Jaminan) } \\
\hline 12. Kejujuran pengurus koperasi & 3,67 & 3,75 & 13,76 \\
\hline 13. Keterampilan/pengetahuan pengurus & 3,68 & 3,57 & 13,13 \\
\hline 14. Pembagian SHU secara adil & 3,66 & 3,79 & 13,87 \\
\hline 15. Transparansi laporan hasil usaha & 3,65 & 3,66 & 13,35 \\
\hline 16. Keramahan pengurus dalam melayani anggota & 3,55 & 3,76 & 13,34 \\
\hline \multicolumn{4}{|l|}{ Dimensi Responsiveness (Daya Ketanggapan) } \\
\hline 17. Persyaratan yang mudah untuk menjual barang ke koperasi & 3,70 & 3,71 & 13,72 \\
\hline 18. Pembayaran penjualan barang yang cepat & 3,67 & 3,67 & 13,46 \\
\hline $\begin{array}{l}\text { 19. Terdapat sanksi untuk anggota yang tidak mematuhi aturan } \\
\text { koperasi }\end{array}$ & 3,68 & 3,63 & 13,35 \\
\hline 20. Penyampaian informasi secara jelas oleh pengurus & 3,64 & 3,70 & 13,46 \\
\hline $\begin{array}{l}\text { 21. Kecepatan dan ketepatan pengurus dalam menanggapai } \\
\text { keluhan anggota }\end{array}$ & 3,72 & 3,68 & 13,68 \\
\hline \multicolumn{4}{|l|}{ Dimensi Emphaty (Perhatian) } \\
\hline 22. Bingkisan Hari Raya & 3,68 & 3,61 & 13,28 \\
\hline 23. Peminjaman sarana produksi (pupuk, pestisida, benih, dll) & 3,51 & 3,44 & 12,07 \\
\hline 24. Kesabaran anggota dalam melayani dan merespon anggota & 3,62 & 3,64 & 13,17 \\
\hline 25. Keramahaan pengurus dalam melayani anggota & 3,66 & 3,70 & 13,54 \\
\hline $\begin{array}{l}\text { 26. Bantuan sosial seperti biaya rumah sakit bila ada anggota } \\
\text { yang sakit }\end{array}$ & 3,51 & 3,42 & 12,00 \\
\hline Total & 93,95 & & 340,1 \\
\hline
\end{tabular}

Sumber : Data Primer Penelitian, 2017

beranggapan bahwa dengan kualitas atau mutu barang yang baik dapat memberikan dampak positif. Hasil penelitian ini sesuai dengan pendapat Supranto (2006) yaitu bentuk pelayanan yang baik dapat menimbulkan prestasi kinerja yang diberikan. Dimensi Realiability memiliki harapan tertinggi sebesar 3,71 hal ini menunjukkan bahwa didalam dimensi ini dirasa berhasil dalam memeberikan pelayanan yang diberikan karena menurut pendapat Subagyo (2010) kehandalan merupakan suatu kemampuan dalam memberikan pelayanan yang telah dijanjikan dengan segera, akurat dan memuaskan. Dimensi Assurance memiliki beberapa atribut yang dirasa 
berpengaruh untuk mendapatkan kepuasaan, skor tertinggi harapan dimensi ini terdapat pada keterampilan atau pengetahuan pengurus sebesar 3,68. Triasmoro dalam Siswono (2017) yang menyatakan bahwa pengurus memiliki kemampuan (keterampilan, pendidikan, pengetahuan, kecekatan) memiliki pengaruh yang sifnifikan untuk meningkatkan kinerja pengurus. Pengurus yang berpengalaman keterampilan atau pengetahuan mampu menciptakan SDM yang sebelumnya belum muncul, hal ini sesuai Fandy (2005) didalam kualitas pelayanan proses kerja dan pengalaman merupakan salah satu dari tujuh faktor yang ada seperti nilai budaya, sistem bisnis serta kepastian jumlah anggota.

Harapan pada dimensi Responsiveness adalah suatu kemampuan untuk membantu dan memberikan pelayanan secara cepat dan tepat kepada pelanggan dengan melalui penyampaian informasi yang jelas. Jika dilihat dimensi ini memiliki skor tertinggi pada kecepatan dan ketepatan pengurus dalam menanggapi keluhan sebesar 3,72 karena jika dilihat anggota yang puas terhadap kinerja pengurus dengan melakukan respon cepat dan tepat terhadap keluhan secara tidak langsung anggota sudah menikmati fasilitas yang sudah diberikan koperasi (Fandy, 2012). Dilihat dari dimensi emphaty memiliki nilai tertinggi sebesar 3,68 yaitu mendapatkan bingkisan Hari Raya. Anggota dengan adanya bingkisan Hari Raya dirasa membuat anggota merasa puas, karena ketika anggota memahami dan mengerti antara pengurus dan anggota dengan berbagai kondisi sehingga terciptanya hubungan yang baik dan mampu memberikan rasa empati melalui bingkisan Hari Raya (Farah, 2003).

Berdasarkan Tabel 8 hasil penjumlahan keseluruhan atribut sebesar 340,1 dan nilai kepentingan dengan rumus (2) diperoleh Indeks kepuasaan Konsumen (CSI) secara keseluruhan diperoleh skor $72,40 \%$ yang sudah dilihat dalam kelima dimensi (Tangibles, Reliability, Responsiveness, Asurance, Emphaty) merupakan salah satu kunci dalam menciptakan suatu loyalitas dan dapat mencegah terjadinya perputaran anggota, mengurangi kegagalan pemasaran, mengurangi biaya operasional sehingga jasa yang sudah diberikan koperasi kepada konsumen sudah puas. Jika dilihat secara keseluruhan Koperasi Gardu Tani melalui pengurus sudah memberikan pelayananpelayanan yang memuaskan anggota untuk mengunjungi koperasi. Anggota yang menikmati pelayanan koperasi akan menentukan kualitas pelayanannya. Hal ini sesuai dengan pendapat Aryani dan Rosinta (2011) bahwa anggota dalam membentuk loyalitas kepuasaan memberikan suatu pengaruh signifikan yang telah diberikan didalam kelima dimensi pembentukan kualitas pelayan. Setelah koperasi mengetahui atribut yang perlu diperbaiki, pengurus melakukan evaluasi-evaluasi, hal ini dilakukan berguna untuk bahan acuan atau pertimbangan kemajuan koperasi. Hal ini sesuai dengan pendapat Irawan (2002) bahwa pengukuran analisis ini diperlukan karena hasil pengukuran ini sebagia acuan untuk memperbaiki sasaran atribut pelayanan yang akan datang.

\section{SIMPULAN DAN SARAN}

Berdasarkan hasil penelitian yang sudah dilakukan mengenai tingkat kepuasan terhadap pelayanan koperasi dapat disimpulkan bahwa $72 \%$ responden berjenis kelamin laki-laki dengan rentang usia 30-50 tahun dan sebanyak 50\% tingkat pendidikan masih rendah. Berdasarkan atribut pada tingkat harapan responden seperti penamilan kerapihan pengurus koperasi (Dimensi Tangibles), pelaksanaan Rapat Anggota Tahunan (RAT) dan pembagian Sisa Hasil Usaha (SHU) tepat waktu (Dimensi Reliability), keterampilan/ pengetahuan pengurus (Dimensi Assurance), kecepatan dan ketepatan pengurus dalam menanggapi keluhan anggota (Dimensi Resposiveness) dan bingkisan hari raya (Dimensi Empathy) dalam hasil penjumlahan keseluruhan atribut sebesar 340,1 dan nilai kepentingan dengan rumus (2) diperoleh Indeks kepuasaan 
Konsumen (CSI) secara keseluruhan diperoleh skor $72,40 \%$ yang sudah dilihat dalam kelima dimensi (Tangibles, Reliability, Responsiveness, Asurance, Emphaty) nilai ini menunjukkan bahwa anggota memiliki rasa puas terhadap pelayanan yang diberikan Koperasi Gardu Tani walaupun belum maksimal.

Kemudian melalukan evaluasi ulang terhadap kinerja yang dilakukan pengurus adalah sangat penting, dengan melalukan evaluasi perbaikan kinerja maka akan menjadi prioritas utama dan meningkatkan pelayanan agar dapat memperhitungkan kepentingan yang diharapkan pengurus.

\section{DAFTAR PUSTAKA}

Aryani, D. dan Febrina, R. 2011. Pengaruh Kualitas Layanan Terhadap Kepuasan Pelanggan dalam Membentuk Loya litas Pelanggan. J. Ilmu Administrasi dan Organisasi. 17 (2): 114-126.

Fandy, T dan G. Chandra. 2012. Service Management Mewujudkan Pelayanan Prima. Edisi II Andi, Yogyakarta.

Fandy. 2005. Service Quality and Satisfaction. Andi, Yogyakarta.

Farah, M. 2003. Tinjauan Persepsi Manajemen Terhadap Struktur Modal Perusahaan Go Public. J. Media Riset Bisnes dan Manajemen. 3 (1): 98-115.

Irawan, H. 2002. 10 Prinsip Kepuasan Pelanggan. PT Elex Media Komputindo, Jakarta.

Lodhita, H. E. 2014. Analisis pengaruh kualitas pelayanan terhadap kepuasan konsumen menggunakan metode IPA (Importance Performance Analysis) dan CSI (Customer Satisfaction Index) Case Study on Toko Oen, Malang. Fakultas Teknologi Pertanian. Universitas Brawijaya. Malang.

Lupiyoadi, R. 2014. Manajemen Pemasaran Jasa: Berbasis Kompetensi. Edisi III, Salemba Empat, Jakarta.
Riani, E. D. 2007. Kinerja Koperasi berdasarkan Kep.Men.No.129/KEP/M/ KUKM/XI/2002, Hambatan, Permasalahan dan Implementasinya (Studi Kasus pada Koperasi Pegawai RI SeKabupaten Pemalang. Fakultas Ekonomi Universitas Negeri Semarang. Semarang.

Ropke, J. 2000. Ekonomi Koperasi. Salemba Empat, Jakarta.

Singarimbun, M dan S. Efendi. 2006. Metode Penelitian Survai. Jakarta (ID): Penerbit Strategi Kepuasan Pelanggan Plus Analisis Kasus PLN-JP. Gramedia, Jakarta.

Siswono A., Sriroso S. dan B. M. Setiawan. 2017. Pengaruh karakteristik penyuluh, kondisi kerja, motivasi terhadap kinerja penyuluh pertanian dan pada perilaku petani padi di Kabupaten Rembang. J. Agrisocionomics. 1(2): 159-173.

Subagyo, A. 2010. Marketing in Business Studi Kasus UMK \& LKM (Usaha Mikro Kecil \& Lembaga Keuangan Mikro). Edisi I. Mitra Wacana Media, Jakarta.

Sugiyono. 2013. Metode Penelitian Pendidikan. Alfabeta, Bandung.

Sunarto. 2006. Manajemen Koperasi. Amus, Yogyakarta.

Supranto, J. 2001. Pengukuran Tingkat Kepuasan Pelanggan. PT. Rineka Cipta, Jakarta.

Supranto. 2006. Pengukuran Tingkat Kepuasan Pelanggan. Cetakan Ketiga. Rineka Cipta, Jakarta.

Umar, H. 2003. Riset Pemasaran dalam Perilaku Konsumen. PT Gramedia Utama, Jakarta.

Wayan, A. P. 2008. Pengaruh Kualitas Pelayanan Terhadap Kepuasan Pelanggan di Pizza Hut Gatot Subroto Denpasar. J. Forum Manajemen. 6 (2): 43-55. 